\title{
Aplicación de los principios de proporcionalidad y legalidad en el derecho disciplinario al momento de la tasación de la sanción disciplinaria para los funcionarios de la rama judicial*
}

\author{
Application of the principles of proportionality and legality \\ in the disciplinary law, at the time of the appraisal of \\ the disciplinary sanction for the officials of the judicial branch
}

\author{
Sandra Milena López López** \\ Karen Alicia Paba López*** \\ Alexandra Victoria González $z^{* * *}$
}

Fecha de recepción: 15 de febrero de 2018

Fecha de aprobación: 10 de abril de 2018

\section{RESUMEN}

La correcta aplicación del principio de proporcionalidad en materia disciplinaria, ha generado una serie de conflictos para el juez disciplinario al momento de sancionar a los funcionarios de la Rama Judicial, presentándose en algunas ocasiones una fuerte tensión con otros

* El presente artículo es producción académica del proyecto de investigación: "El principio de proporcionalidad en el derecho disciplinario colombiano respecto de los funcionarios de la rama judicial”, en el marco del programa de la Maestría en Derecho Administrativo de la Universidad Libre, Bogotá D. C., Colombia. DOI: http:// dx.doi.org/10.15332/s1909-0528.2018.0002.05

** Abogada de la Universidad Libre, Bogotá D. C., Colombia. Magíster en Derecho Administrativo de la misma Universidad. Especialista en Derecho Administrativo de la Universidad Externado de Colombia. Adelanta actualmente especialización en Responsabilidad Civil y del Estado en la Universidad de la Sabana. Magistrada auxiliar de la Sala Jurisdiccional Disciplinaria. Correos electrónicos: slopezl2012@gmail.com, samy07lopez30@hotmail.com.

*** Abogada de la Universidad Libre, Bogotá D. C., Colombia. Magíster en Derecho Administrativo de la misma Universidad. Especialista en Derecho Administrativo de la Universidad Libre, Bogotá D. C., Colombia. Correo electrónico: karenpaba@yahoo.com

**** Abogada de la Universidad Libre, Bogotá D. C., Colombia. Magíster en Derecho Administrativo de la misma Universidad. Correo electrónico: alexavic@hotmail.com 
principios legales y constitucionales, por lo cual se pretende con este documento establecer si en la actualidad se aplican de forma correcta los principios de proporcionalidad y legalidad en materia disciplinaria, específicamente respecto de los funcionarios de la Rama Judicial, investigados y sancionados por los Consejos Seccionales del país en primera instancia, y en segunda, por el Consejo Superior de la Judicatura. Este artículo busca entonces determinar, si los elementos normativos que se encuentran dentro de la Ley 734 de 2002, son suficientes e idóneos en la aplicación adecuada del principio de proporcionalidad en consonancia con el principio de legalidad, al momento de la tasación de las sanciones disciplinarias que se les imponen a los funcionarios públicos de la Rama Judicial. Todo esto desarrollado bajo un marco de investigación sociojurídica, que indaga al interior de la Jurisdicción Disciplinaria —operadores disciplinarios - los fenómenos fácticos y jurídicos que enfrentan al momento de la cuantificación de la sanción, empleando a su vez un método inductivo-deductivo de investigación, analizando varias providencias disciplinarias en las cuales han resultado sancionados funcionarios de la Rama Judicial. Finalmente, esta disertación se desarrollará analizando la aplicación de estos dos principios en el campo disciplinario, legislativo y en los pronunciamientos de la Corte Constitucional, para así presentar una serie de recomendaciones frente al ejercicio de la potestad disciplinaria en las investigaciones a funcionarios de la Rama Judicial.

Palabras clave: principio de proporcionalidad, principio de legalidad, sanción, proceso disciplinario, funcionarios, rama judicial.

\section{Abstract}

The correct application of the proportionality principle in disciplinary matters, has generated a series of conflicts for the disciplinary judge at the moment to sanction the officers of the Judicial Branch, generating in some occasions a strong tension with other constitutional and legal principles, whereby its pretended with this document to stablish if actually the proportionality and legality principles are rightly applied, specifically about the officers of the Judicial Branch, investigated and judged by the Sectional and Superior Councils of the Judiciary. This article pretends then to determine, if the normative elements inside the 734 of 2002 Law, are sufficient and suitable to applicate correctly the proportionality principle harmonically with the legality principle, at the moment to stablish the disciplinary sanction that is imposed to the officers of the Judicial Branch; all this developed under the frame of a 
legal social investigation, that inquires at the bottom of the disciplinary jurisdiction - disciplinary operators - the legal and factual phenomena that they deal with at the moment to quantify the sanction, using at the time an inductive deductive investigation method, analyzing a few disciplinary decisions where officers of the Judicial Branch had been sanctioned. Finally this dissertation will be developed analyzing the application of this two principles in the disciplinary, legislative field and the decisions of the Constitutional Court, to present a series of recommendations facing the application of the disciplinary power in the investigations followed to the officers of the Judicial Branch.

Keywords: proportionality principle, legality principle, sanction, disciplinary process, official, judicial branch.

\section{INTRODUCCIÓN}

En un Estado social de derecho resulta indispensable pensar en la existencia de un marco jurídico en el cual se establezca claramente un régimen de responsabilidad, tanto para los servidores públicos, en sentido general, como para los particulares que coadyuvan a la administración pública, en aras de generar una atmósfera de confianza de lo público ante la sociedad, en la que, la conducta puede ser valorada tanto en su aspecto activo como pasivo; o lo que es lo mismo, en la acción tanto como en la omisión, a fin de que pueda ser sancionada toda conducta que se considere contraria a los principios y expectativas de la función pública, en lo que respecta a la correcta actuación de los servidores públicos como género, pero que para el caso de este artículo se circunscribirá en torno a la especie, de los funcionarios de la Rama Judicial y cómo sus jueces naturales deben hacer la ponderación de principios de raigambre constitucional en los juicios de responsabilidad disciplinaria que enfrentan en su día a día.

Desde el punto de vista constitucional, esta garantía se erige como pilar fundamental para asegurar a la ciudadanía, la posibilidad de que sus funcionarios judiciales cumplan con sus funciones y sus deberes para con el Estado, en un marco regulatorio que limite dichas funciones y evite y sancione las conductas que desborden las mismas. En ese sentido, lo considera en su artículo sexto el régimen de responsabilidad constitucional (Constitución Política de Colombia), en cuyo texto se hace referencia a los 
compromisos de los particulares que contribuyen con las actividades de la función pública y de los funcionarios del Estado.

Las pautas otorgadas por nuestra Constitución Política, se materializan entonces en el sistema disciplinario colombiano, siendo su principal exponente el actual Código Disciplinario Único contemplado en la Ley 734 de 2002, que tiene como propósito general el establecimiento de medidas preventivas y correctivas, de aquellas acciones u omisiones que atenten contra la moralidad de la función pública y de los principios constitucionales establecidos para esta.

Ahora bien, el uso del ius puniendi en el caso del sistema disciplinario ${ }^{1}$, al igual que en otras ramas del derecho donde se hace uso de esta potestad sancionadora, se debe ajustar a los parámetros y principios constitucionales establecidos para efectos de realizar una correcta sanción a los funcionarios judiciales que atenten contra la función pública. Dentro de estos principios, se encuentran el principio de proporcionalidad y el principio de legalidad, que para el caso concreto, se materializan en la asignación de la sanción que se impone al disciplinable al momento de cometer alguna de las faltas señaladas por la Ley 734 de 2002, o incumplir los deberes y prohibiciones descritos en la Ley 270 de 1996, y en la interpretación que frente a cada caso concreto realiza el juez disciplinario.

Sobre la aplicación de este principio de proporcionalidad en consonancia con el principio de legalidad, es que se asienta la presente investigación, cuyo propósito principal es el de analizar si existe en la actualidad una correcta aplicación de dichos principios al momento de imponer sanciones, para el caso de los funcionarios de la Rama Judicial investigados y juzgados por las Salas Jurisdiccionales Disciplinarias y de los Consejos Seccionales del país.

Es importante resaltar que para el estudio y desarrollo de esta investigación, desde la investigación cualitativa, se ha estimado la utilización de varios métodos de investigación científica para recolectar la información necesaria, lo cual ha sido corroborado

1 Es importante considerar de conformidad con Hernández (2018), que: "La autonomía del juez en sus decisiones no es absoluta ni fácil, sus decisiones están marcadas por reglas, principios, juicios de valor y posturas filosóficas que en una determinada eventualidad resultan mal entendidas, erróneamente aplicadas o indebidamente consentidas y de contera trasgreden derechos de los autores en la atmósfera judicial” (p. 213). 
y permitido por parte de la doctrina jurídica (Huertas, Rumbo y Uribe, 2018), partiendo del análisis jurisprudencial de la temática expuesta en el manuscrito.

\section{DEL PRINCIPIO DE PROPORCIONALIDAD EN LA JURISDICCIÓN DisCIPLINARIA}

Enmarcada la finalidad de este artículo, se hace necesario entonces establecer cuál es la aplicabilidad de los pluricitados principios en el caso de las sanciones disciplinarias de manera general y específica, para el caso de los servidores públicos de la Rama Judicial.

Con ello, se busca abordar los principios de proporcionalidad y legalidad a partir de la norma, la doctrina y la jurisprudencia (Corte Constitucional), con el propósito de mostrar al lector los rasgos esenciales que constituyen estos principios en el campo del derecho disciplinario ${ }^{2}$, en especial el que los erige como el límite jurídico que bajo ninguna circunstancia puede ser obviado por el operador jurídico al momento de evaluar cada caso concreto, y que se constituye en la medida idónea para evitar la configuración de posibles discrecionalidades y subjetividades al momento de la imposición de la sanción.

\section{El principio de proporcionalidad en el ámbito disciplinario}

El principio de proporcionalidad, es una concreción del denominado principio de legalidad, y funge como la medida que por excelencia limita la discrecionalidad y arbitrariedad de la facultad sancionadora del Estado. Su esencia es la de prohibir desde la ley, el exceso en la imposición de sanciones y su concordancia con el hecho que la causa. Al respecto, Roa (2014) señala que el principio de legalidad no solo

2 Al respecto y de conformidad con Bahamón y Gómez (2017), es importante resaltar: "En el ámbito del derecho público, uno de los hechos trascendentales es el enorme desarrollo que ha tenido el derecho disciplinario, al punto en que se puede hablar de un derecho sancionador autónomo e independiente con características y fundamentos propios que lo distinguen del derecho administrativo y del derecho penal; evolución que se debe a los pronunciamientos de las altas cortes, a las decisiones de la Procuraduría General de la Nación y a todos aquellos aportes que desde la doctrina se han realizado" (p. 145). 
puede limitarse a que "[...] los comportamientos por los que resultan investigados el servidor público y el particular disciplinable estén previamente descritos como falta, debiendo extenderse a la legalidad de su sanción, conforme a la calificación jurídica que se haga de aquella" (p. 141).

En Colombia, el principio de proporcionalidad se encuentra regulado en varias disposiciones y en todos los campos del derecho. Es así como en el campo del derecho disciplinario, se encuentra en el artículo 18 de la Ley 734 de 2002, que señala "la sanción disciplinaria debe corresponder a la gravedad de la falta cometida. En la graduación de la sanción deben aplicarse los criterios que fija esta ley".

De acuerdo con la exposición de motivos que precedió a la promulgación de la Ley 734 de 2002, la consagración del principio de proporcionalidad se hacía necesaria al pretender " $[\ldots]$ poner fin a las inequidades que permite la legislación actual, debido, entre otros aspectos, al escaso número de conductas que dan lugar a destitución, y para garantizar que las sanciones disciplinarias correspondan a la gravedad de las faltas [...]" (Congreso de la República, Proyecto de Ley No 19 de 2000)³.

Su contemplación dentro de la legislación disciplinaria, deja entrever la preocupación del legislador en el establecimiento de límites a la potestad sancionadora del Estado frente a sus funcionarios, buscando con ello que fuera la misma ley la que indicara criterios taxativos para la graduación de la sanción disciplinaria y su correspondencia con la falta cometida.

Ahora, precisamente la relevancia del principio de proporcionalidad lo lleva a subdividirse en tres elementos o subprincipios, a saber: adecuación, necesidad y proporcionalidad en sentido estricto, los cuales deben ser evaluados en cada evento donde el Estado haga uso del ius puniendi. Lo anterior entonces significa, que el principio de proporcionalidad "[...] implica que existe una ecuación perfecta, una aritmética simetría entre la conducta perpetrada por el infractor y la calidad y cantidad de sanción impuesta, y ello lo que presupone es la formulación de un juicio de propor-

3 En concordancia con lo dispuesto por Bonilla (2018), es procedente anotar que "Quiérase o no, la nueva legislación procesal implica cambios de paradigmas, cultura, actitud y pensamiento jurídicos que solo podrán ser realizados plenamente si estamos dispuestos a abandonar los viejos modelos. Consideramos que esta es una condición sine qua non para poder solventar las dudas en la forma de aplicar las nuevas reglas procesales" (p. 219). 
cionalidad concreto" (López, 2013, p. 75), y que se ajuste a los postulados de prohibición de exceso en el uso de la potestad sancionadora del Estado, y así impedir “[...] los excesos o abusos de poder que podrían provenir del empleo indiscriminado de la facultad legislativa o de la discrecionalidad atribuida a la administración" (Corte Constitucional, Sentencia C-393 de 2006).

En primer lugar, el operador jurídico debe evaluar la idoneidad de la sanción disciplinaria, y cotejar esta con el fin que se propone o persigue, lo cual se traduce en que su imposición persiga un fin legítimo y que sea acorde con el hecho que la causa. En segundo lugar, la sanción disciplinaria debe ser necesaria, así como se debe justificar el que no exista otra de menor entidad que cumpla con el mismo propósito y que sea menos invasiva en lo que respecta a los derechos del disciplinado. En tercer lugar, se encuentra el juicio de proporcionalidad en sentido estricto, que no es otra cosa que una ponderación entre los beneficios que trae consigo la imposición de la sanción disciplinaria y sus perjuicios, siendo preminentes los beneficios, conllevando a la razonabilidad.

Así las cosas, la sanción disciplinaria para que pueda considerarse proporcionada, debe superar todos los subprincipios que componen el juicio de proporcionalidad. Es por ello que para que una sanción disciplinaria pueda considerarse como idónea, necesariamente debe apuntar a la consecución de un fin que sea constitucionalmente válido, por haberse puesto en vilo un bien jurídico protegido, que para el caso concreto, se traduciría en la función pública. Luego de que ello es determinado, y en lo que respecta al elemento de la necesidad, la sanción disciplinaria debe obligatoriamente ser la menos lesiva para los derechos del disciplinado. Para poder determinar ello, Valdés, Cárcamo, Tirado, Osorio y Muñetón (2007), sugieren efectuar un análisis en dos sentidos, que consista

\footnotetext{
[...] primero, en comparar si alguna de las sanciones alternativas es igualmente idónea a la consagrada en la norma y, segundo, si esa condición afecta algún principio constitucional, en un grado menor; luego, el primer paso en la aplicación de este subprincipio es la elección de sanciones alternativas (p. 72).
}

Finalmente, cuando se trata el elemento de la proporcionalidad en sentido estricto, el operador jurídico debe evaluar que la sanción que se dispone a imponer, se justifique 
en la medida en que con esta se obtenga un beneficio mayor y que este se sobreponga a la satisfacción de las garantías individuales del infractor. Al respecto, Valdés et ál. (2007) acotan que: "[...] la aplicación de la proporcionalidad, en sentido estricto, significa que las ventajas que se obtienen mediante la imposición de una sanción deben compensar los sacrificios que dicha sanción implica para los derechos y garantías fundamentales del disciplinado" (p. 72).

\section{Etapas del juicio de proporcionalidad en el derecho disciplinario}

La primera etapa del juicio de proporcionalidad se da al momento de regular el uso de la facultad sancionadora del Estado, en cabeza del legislativo, para lo cual deberá hacerse un juicio de tal principio frente a las faltas que busca tipificar y las sanciones de cada una de estas, así como la justificación de la protección del bien jurídico y la necesidad de estas medidas correctivas. Dentro de este juicio de proporcionalidad, el legislador debe optar — en la medida de lo posible — por la protección del bien jurídico, con la menor intervención posible de las libertades y garantías de los individuos.

Aun cuando el correcto ejercicio de la función pública puede tener connotaciones en el derecho penal, el legislador ha optado por proteger esta, mediante el derecho disciplinario, principalmente porque las acciones u omisiones de sus funcionarios pueden causar (aunque no es necesario un resultado) un daño a la administración, que no puede ser obviado por encontrarse relacionados intereses colectivos.

Dentro de este proceso de adecuación típica de las faltas, el legislador se encuentra en el deber de clasificar las faltas o infracciones de acuerdo a la importancia de estas, al mayor riesgo generado frente a un posible resultado dańoso, entre otros elementos que involucran un juicio de proporcionalidad entre lo que es necesario disciplinar y lo que no, y cuáles de estas faltas disciplinables merecen una mayor sanción y cuáles pueden ser sancionadas con menor severidad.

Si bien el legislador cuenta con una amplia autonomía en la configuración de las leyes, que descansa en el poder soberano otorgado del pueblo, su función legislativa no es de carácter absoluto. El límite de su actuación, cuando se trata de regular la 
facultad sancionadora del Estado, se encuentra centrado en el respeto mínimo de los principios, derechos, libertades y garantías constitucionales y de los derechos humanos del sujeto, contenidos en el mismo bloque de los tratados ratificados por Colombia, así como de los hechos que este considera deben ser sujetos a una sanción disciplinaria. En ese sentido, también lo considera la Corte Constitucional al señalar que el legislador en uso de sus funciones debe siempre adoptar " $[\ldots]$ procedimientos proporcionados, ajustados a la realidad de los hechos y a la calidad de los sujetos que intervienen en los procedimientos" (Corte Constitucional, Sentencia C-738 de 2006).

En la Sentencia C-125 del año 2003, la corporación guardiana de la Constitución también señaló que el principio de proporcionalidad en el derecho sancionador demanda que: "[...] tanto la falta descrita como la sanción correspondiente a la misma resulten adecuadas a los fines de la norma, esto es, a la realización de los principios que gobiernan la función pública”. Así las cosas, es tarea del legislador durante la construcción de la falta y la sanción y en la descripción de las conductas en la ley, bien sea por acción y omisión, que estas sean acordes con la finalidad de la norma, por lo cual Ramírez (2010) sugiere que en las leyes se determinen criterios para dosificar la sanción, tales como "[...] la naturaleza de la infracción, el grado de la intención en la comisión de la misma; la gravedad del peligro creado o de los dańos producidos; la reparación voluntaria del daño ocasionado; la reincidencia, la reiteración, etc." (p. 163).

Es el legislador el llamado a considerar estos criterios, y a velar porque estos se ajusten a la realidad fáctica al momento de la confección de las leyes disciplinarias, a fin de que puedan ser considerados como proporcionales y razonables. Ello, en el ámbito del derecho disciplinario, se ha venido manejando con la clasificación de las faltas que realiza el legislador en el Código Disciplinario Único del año 2002 y de las sanciones que consideró convenientes para estas, introduciendo no solo dicha clasificación, sino también el grado de intencionalidad con las que se realizan, como otro criterio para que el operador jurídico pueda proyectar una sanción dentro de los límites definidos por el principio de proporcionalidad.

Es de tal importancia que existan criterios claros para la aplicación del principio de proporcionalidad de las sanciones dentro de la legislación, que de una falencia en 
ello, podrían degenerarse actuaciones discrecionales, subjetivas y hasta arbitrarias por parte de los operadores disciplinarios. Es por esto que algunos autores como García (2007) consideran que no "[...] basta con una simple previsión genérica de sanciones posibles sino que es necesaria una correlación precisa entre las infracciones y sin graduación de estas, se deje abierta a la autoridad sancionadora la elección entre un catálogo de sanciones genéricamente previstas" (p. 166). La generalidad en la estipulación de las sanciones por parte del legislador, abre paso a que pueda haber una interpretación disímil con el fin de la norma, cuando se trata de la proporcionalidad de esta frente a la falta que se pueda configurar al interior de la investigación disciplinaria. Tal como lo considera Santamaría (2004), podría darse el caso de que "[...] las conductas idénticas podían ser teóricamente reprimidas con multas de muy diverso volumen" (p. 397).

Por otro lado, la segunda etapa en la que se presenta el juicio de proporcionalidad, es cuando se impone la sanción al disciplinado. En el seno de dicha actuación disciplinaria, es donde se demanda que quien la impone adecúe en la medida la menos lesiva posible, la sanción contemplada en la ley para la falta cometida, entendiéndose esta actividad como la regla general al ejercicio de interpretación y análisis que debe desprenderse del operador disciplinario. Por supuesto que esta potestad de imponer sanciones, no solo debe ajustarse a lo estipulado por el legislador —en atención al principio de legalidad-, sino que también debe realizarse dentro de los preceptos indicados por el principio de proporcionalidad, como se señaló en líneas anteriores. La Corte Constitucional al respecto ha indicado que: "[...] el poder que se reconoce a la administración, para la aplicación de estas normas, no es ilimitado y discrecional, pues, la función sancionadora debe ejercerse dentro de los límites de la equidad y la justicia" (Sentencia C-160 de 1998).

$\mathrm{Al}$ igual que el juicio de proporcionalidad realizado por el legislador —en lo atinente a la sanción-, el funcionario con la potestad disciplinaria debe en primer lugar buscar la adecuación de la misma, y en segundo lugar —al momento de imponerla-, evaluar la idoneidad, necesidad y razonabilidad de esta, frente a la gravedad de la falta y al bien jurídico que se busca proteger. En estos eventos, el operador jurídico debe analizar lo que la norma le indica frente a la situación fáctica y la sanción contemplada para esta y si la falta señala para cada caso concreto una sanción específica 
(como sucede en el derecho penal). En esa situación, la norma misma es la que indica cómo debe imponerse la sanción y el juicio de proporcionalidad solo se remite a una dosimetría entre mínimos y máximos, asemejándose más a una aplicación directa del principio de legalidad y limitando severamente el juicio de proporcionalidad, lo que de por sí se considera más sano para evitar subjetividades o decisiones arbitrarias o discrecionales. En ese sentido también lo considera Ramírez (2010), al afirmar:

[...] la Corte ha realizado una interpretación conjunta de dos principios constitucionales como lo son: el de legalidad y de proporcionalidad, en el sentido que afirma que en las circunstancias en que exista tal escala para calificar la infracción y la sanción en la ley, se debe estar al tenor de la disposición legal — consecuencia del respeto del principio de legalidad—, siendo imperativo que la autoridad administrativa las califique de acuerdo con los parámetros allí establecidos (p. 167).

Ahora bien, en el caso del derecho penal, estos postulados se definen en sanciones independientes en cada caso concreto, con parámetros claros de asignación de la pena, en mínimos y máximos. Pero no sucede lo mismo en el derecho disciplinario, principalmente porque la Ley 734 de 2002, aun cuando fija parámetros de asignación de las sanciones, los realiza de manera general, permitiendo al operador jurídico un margen amplio de interpretación frente a la apreciación de los hechos, su adecuación y la imposición de la sanción, criterios definidos por el artículo 47 de la anterior Ley. Sumado a ello, aun cuando existe una enunciación del principio de proporcionalidad como rector de la acción disciplinaria y unos calificativos que se desprenden del artículo 42 y subsiguientes para la aplicación de este principio, su interpretación en la asignación de la sanción depende en gran medida del juicio de valor que realiza el operador jurídico, poniendo entonces la responsabilidad de la asignación de la sanción en su subjetividad y discrecionalidad.

Ello en cierta medida ha sido aceptado por la Corte Constitucional, siempre y cuando la subjetividad del operador jurídico no desconozca lo reglado por el legislador o el principio de proporcionalidad de la sanción. En ese sentido, lo expresa en la Sentencia T-1093 de 2004 al precisar que: “(...) únicamente desconocerán estos márgenes aquellas calificaciones de la falta y su nivel de gravedad que no encuentren un fundamento en la normatividad aplicable, o que sean evidente y manifiestamente irrazonables frente a la situación objeto de evaluación”. 
El segundo momento en que el operador disciplinario debe hacer uso del principio de proporcionalidad, es cuando efectivamente se hace la imposición de la sanción. En ese caso, es en donde se deben evaluar nuevamente los postulados del principio de proporcionalidad y verificar el cumplimiento de todos y cada uno de ellos; o lo que es lo mismo, comprobar la idoneidad, necesidad y razonabilidad de la sanción, así como su cumplimiento de cara al postulado establecido por la Sentencia C-125 de 2003, en el sentido de que esta no puede ser excesivamente rígida "[...] frente a la gravedad de la conducta, ni tampoco carente de importancia frente a esa misma gravedad", lo que en otras palabras quiere decir equilibrada y equitativa.

Este juicio de proporcionalidad, al igual que los demás actos o decisiones donde se involucre la disminución de algún derecho, por supuesto debe encontrarse justificado y motivado, de forma tal, que de la argumentación puedan determinarse sin lugar a dudas las razones que justifican y hacen proporcionada la sanción impuesta y que obligatoriamente deben ser concordantes con los hechos originarios de la sanción, es decir, los constitutivos de falta disciplinaria.

\section{Del PRINCIPIO DE LEGALIDAD EN LA JURISDiCCIÓN DisCIPLINARIA}

En este capítulo, desarrollaremos una relación jurisprudencial, legislativa y doctrinal sobre la aplicación del principio de legalidad en la investigación disciplinaria, en aras de establecer la relevancia que tiene en la actuación procesal y su impacto en la prevalencia del mismo principio de proporcionalidad, en tanto el artículo 18 del Código Disciplinario Único (CDU), señala claramente que la sanción debe corresponder a la gravedad de la falta y su graduación depende de los criterios fijados por la ley, esto quiere decir, que las conductas reprochables disciplinariamente deben estar descritas como faltas en el ordenamiento jurídico, y por ende, su sanción también.

\section{Principio de legalidad de la rama legislativa en el ámbito disciplinario}

Durante el trámite legislativo de la Ley 734 de 2002, el legislador conoció desde su exposición de motivos los vacíos presentados por la Ley 200 de 1995, pues solamente se sancionaban faltas gravísimas con destituciones y quedaban con castigos irriso- 
rios conductas graves que afectaban el funcionamiento de la administración pública, como era el caso de "existencia de intereses personales en la celebración de contratos estatales" ", siendo este momento histórico en el cual se planteaban regímenes propios para el derecho disciplinario, como fue el de las sanciones y de las faltas — para el caso de las Fuerzas Militares—, destacándose como "principio rector de la función pública la sanción administrativa disciplinaria" como herramienta útil para el cumplimiento de los fines "legales y constitucionales que deben observarse al ejercer la función pública”.

Frente al principio de legalidad, el legislativo encontró desde las ambigüedades presentadas por la Ley 200 de 1995, que ante el escaso número de conductas que daban lugar a la destitución, se debía edificar un principio con el cual se garantizara “... que las sanciones disciplinarias correspondan a la gravedad de las faltas", brindándole al operador disciplinario un principio rector para determinar el tipo de sanción y su quantum, evitando que las conductas más graves fueran sancionadas irrisoriamente, mientras que las más leves de forma severa, por esto, según el tipo de falta — gravísima, grave o leve—, y la forma de culpabilidad —dolo, culpa—, se decantaba el tipo de sanción a imponerse.

Respecto al catálogo de faltas, los ponentes de la ley encontraron que la legislación anterior al CDU, solamente enunciaba un escaso listado de faltas gravísimas, dejando por fuera un sinnúmero de conductas que debían ser reguladas debido a las condiciones sociales y culturales que enfrentaba la administración pública y que no estaban contenidas en ningún decálogo; por ello se incrementaron las faltas gravísimas, con los listados de deberes y prohibiciones de forma descriptiva y detallada, buscando no dejar por fuera de la sanción disciplinaria ningún comportamiento irregular de los servidores públicos y particulares.

Ahora, el proyecto de ley traía consigo un régimen de sanción. Sin embargo, dado el detrimento ético y moral advertido en el ejercicio de la función pública, por la corrupción administrativa y el desconocimiento de los derechos de los ciudadanos, evidenciándose que: "Si los abusos del poder público no se enfrentan con sanciones

4 Régimen Legal de Bogotá D. C. (febrero de 2018). Exposición de motivos 734 de 2002, nivel nacional. Más información en http://www.alcaldiabogota.gov.co/sisjur/normas/Normal.jsp?i=11412\#0 
disciplinarias fuertes, este se desborda, escapa a todo control y se torna definitivamente arbitrario". Por esta razón, se cubrieron lo yerros advertidos en la Ley 200 de 1995 y se le imprimió término a la inhabilidad general de 5 a 20 años, a las faltas graves dolosas sancionadas con suspensión e inhabilidad especial por el mismo término de la suspensión — que no podría ser inferior a un mes ni superior a un año-, poniendo fin a una practica del sancionado al ser nombrado en otro cargo, destacándose en la exposición de motivos del CDU que: "El sistema propuesto, a diferencia del actual, en la determinación de la sanción tiene en cuenta el grado de culpabilidad del autor al cometer la falta, que constituye otra aplicación de la proporcionalidad que debe existir entre conducta y sanción”.

En suma, el legislador encontró que con la Ley 200 de 1995 era imposible imponer sanciones severas a conductas que estaban atentando contra el orden y ejercicio de la función pública en todos los niveles, en tanto no existía un catálogo de faltas más amplio que supliera esas necesidades, ni tampoco existía claridad acerca de las sanciones que debían imponerse. Precisamente por dicha razón, se reguló mediante la Ley 734 de 2002 un catálogo más amplio de conductas reprochables, otorgándoseles más relevancia a las faltas graves y leves, y por ende, determinando un nuevo listado de sanciones para las cuales se establecieron límites en los términos de la sanción, dándole mayor prevalencia al postulado rector del artículo 29 de nuestra Constitución de cara a la edificación misma del principio de legalidad en la actuación disciplinaria.

Hoy en día, la Ley 734 de 2002 no solamente contempló un catálogo extenso de faltas gravísimas descritas en el artículo 48, aplicable a todos los servidores públicos en los que están incluidos los funcionarios de la Rama Judicial, quienes además debían velar por el cumplimiento del listado de deberes y prohibiciones contenidos en la Ley 270 de 1996 — artículos 153 y 154_, sino que además con el desarrollo de la Constitución de 1991 — en el marco de un Estado social de derecho que exigía mayor protagonismo de las instituciones en la protección de los derechos humanos frente a las cargas públicas-, se desarrolló directamente en toda la codificación el artículo 29 constitucional, incluyéndolo además como un principio rector en la actuación disciplinaria denominado en el artículo 4 del CDU, "Principio de legalidad".

Ahora, no debe olvidarse que, con la aplicación debida del principio de legalidad, también se materializa la finalidad misma del principio de proporcionalidad, como 
bien lo ha afirmado la Corte Constitucional en la Sentencia C-653 de 2001 al señalar que: "[...] este principio además protege la libertad individual, controla la arbitrariedad judicial y administrativa y asegura la igualdad de todas las personas ante el poder punitivo y sancionatorio del Estado".

Así las cosas, resulta evidente que el principio de proporcionalidad viene a ser una manifestación del principio de legalidad, en tanto limita y salvaguarda la seguridad jurídica de los ciudadanos bajo una clara garantía al debido proceso y derecho de defensa de los actores del proceso disciplinario ${ }^{5}$, quienes a su vez, están regidos por las normas creadas por la competencia legislativa del Congreso para configurar todo el marco de principios, faltas, sanciones y cada uno de los criterios para su aplicación, en la Jurisdicción Disciplinaria, como bien lo manifestó la Corte Constitucional en la Sentencia C-328 de 2015, al afirmar que la competencia legislativa permite al legislador establecer ciertas reglas para asegurar la efectividad de ciertos derechos como al debido proceso, "[...] reglas que, además, buscan consolidar la seguridad jurídica, la racionalidad, el equilibrio y la finalidad de los procesos, al tiempo que permiten desarrollar el principio de legalidad que resulta ser consustancial al Estado social de derecho $[\ldots] "$

En suma, fue la misma potestad del Estado en cabeza del legislativo la que materializó el principio de legalidad en la codificación disciplinaria para sentar bases más sólidas y claras para que el principio de proporcionalidad tuviera el protagonismo debido en pro de los intereses de los investigados quienes cuentan, hoy en día, con un catálogo de faltas y un régimen propio de sanciones que al momento de ponerse en funcionamiento el aparato jurisdiccional, el operador debe impartir una justicia más justa al propender por la aplicación de los principios mencionados.

$5 \mathrm{Al}$ respecto, es importante resaltar en el marco de los derechos referenciados, que: "En la actualidad, el Estado colombiano ha firmado todos los convenios y tratados en materia de derechos humanos, a lo que se agrega que la Constitución Política está fundamentada en un Estado social y democrático de derecho, el cual tiene como pilar el respeto de la dignidad humana. En este mismo sentido, los derechos humanos son reconocidos en todo tiempo y lugar y no pueden suspenderse ni siquiera en los estados de excepción” (Montero, 2017, p. 42). 


\section{Principio de legalidad en la sanción disciplinaria desde la doctrina y la jurisprudencia}

En este contexto, el principio de legalidad reviste una gran importancia en las actuaciones judiciales, que para el caso del derecho disciplinario, se convierte en un blindaje al principio de proporcionalidad, sirviendo como instrumento de valoración al operador disciplinario, en tanto este sabe de antemano que las faltas disciplinarias se encuentran establecidas por el legislador.

Bajo este planteamiento, el panorama no resulta tan sencillo, en tanto el operador disciplinario se enfrenta a una dificultad en su quehacer judicial, como es la calificación de las conductas, para lo cual debe analizar las conductas denunciadas en conjunto con las pruebas allegadas a la actuación, para de esta forma establecer el juicio de reproche por el cual el disciplinado debe responder, es decir, la calificación de su conducta debe encuadrar en los tipos disciplinarios preestablecidos por la ley para los funcionarios de la Rama Judicial. Pero esta actividad metodológica realmente se edifica en la aplicación de los criterios de gravedad o levedad de la falta —artículo 43-, y de otro lado los de definición y graduación de la sanción —artículos 44 al 47 - con lo cual desde ese momento procesal — pliego de cargos — se materializa en sentido estricto, no solamente el principio de legalidad, sino que además, este asegura que con el principio de proporcionalidad no se cometan arbitrariedades con la edificación de calificaciones ambiguas o alejadas de la realidad ya señalada por la ley en los procesos disciplinarios.

Entonces tenemos que, al analizar los principios de proporcionalidad y de legalidad, este último toma una importancia sustancial en la actuación disciplinaria, en tanto para que el primero se cumpla, el segundo debe brindar la certeza de que la ley contenga los criterios de dosimetría de la sanción requeridos por el operador disciplinario en su ejercicio de administrar justicia, como máxima garantía de un Estado social de derecho que propenda por la protección en toda actuación del debido proceso.

Es así que la Ley 734 de 2002, en el desarrollo de nuestro Estado social de derecho, contempló una serie de avances en materia de principios y reglas procesales, integrando en su totalidad el artículo 29 constitucional, al haber dejado plasmado en su artículo 4 el principio de legalidad. 
Siguiendo los derroteros jurisprudenciales del Alto Tribunal en la Sentencia C-125 de 2003, la guardiana de la Constitución indicó sobre la relación directa del principio de legalidad y la función de la sanción disciplinaria que:

Las sanciones imponibles deben perseguir una finalidad disuasoria de conductas que impidan la efectividad de los mencionados principios que rigen la función pública, la punición de las mismas con fines correccionales, o el retiro del servicio de aquellos funcionarios cuya conducta extrema compromete de manera grave la realización de esos principios constitucionales.

Es por esto que algunos autores como García (2007), manifiestan la necesidad de correlaciones directas entre las faltas y sus sanciones indicando particularmente que no "[...] basta con una simple previsión genérica de sanciones posibles sino que es necesaria una correlación precisa entre las infracciones y sin graduación de estas, se deje abierta a la autoridad sancionadora la elección entre un catálogo de sanciones genéricamente previstas" (p. 166), centrándose además la problemática desarrollada en este artículo, en tanto se ha observado que en algunas decisiones de la Jurisdicción Disciplinaria las sanciones impuestas no corresponden a los criterios para su tasación igualmente seńalados por el CDU, y que además, las calificaciones o pliegos de cargos no se edifican bajo bases clara de faltas gravísimas, graves y leves, con lo cual se lesionan los principios de legalidad y proporcionalidad.

\section{El Código General Disciplinario y los PRincipios de PROPORCIONALIDAD Y LEGALIDAD EN LAS SANCIONES}

En el año 2014, algunos estamentos gubernamentales —Procuraduría General de la Nación, Consejo Superior de la Judicatura y Defensoría del Pueblo, entre otros-, notan la necesidad de actualizar las disposiciones del derecho disciplinario a la actualidad del servicio público. La presentación de nuevas formas de vulneración de los principios de la función pública así lo demandaban. El proyecto de ley, tuvo en cuenta nueve aspectos importantes que consideraban debían ser objeto de modificación.

El primero de estos hace relación a la formulación de los principios que rigen el derecho disciplinario. Dentro de las novedades en este aspecto se incluyen y 
desarrollan principios de vital importancia como la dignidad humana, la especialidad y subsidiariedad de la legislación disciplinaria, el complemento de la ilicitud sustancial, la investigación integral, el complemento del derecho a la defensa en todo la actuación disciplinaria y el de congruencia, entre otros.

En materia de proporcionalidad, aun cuando el nuevo proyecto de código no hace mención alguna de forma directa, sí da unos parámetros de cumplimiento de este principio, pues al hacer una lectura del proyecto de ley, se denota un gran avance en la instrucción e investigación en los procesos disciplinarios.

Por otra parte, uno de los cambios más significativos de la reforma en este aspecto, es la definición del dolo y culpa en materia disciplinaria, elementos ausentes o cuestionados dentro de la legislación actual.

Así mismo, la descripción de lo que se considera falta disciplinaria, se encontraba ausente dentro del contenido del articulado de la Ley 734 de 2002. El nuevo texto presenta también algunas modificaciones de la Ley 1474 de 2011 en cuanto a la prescripción que indicaba esta normatividad, dejando los límites en diez (10) años, siete (7) años para el trámite ante primera instancia y tres (3) años para el trámite en segunda instancia. Sin embargo, luego de ser analizada la conveniencia de mantener estos términos, el Congreso decide retornar a lo inicialmente señalado en la Ley 734 de 2002, al considerar que:

\footnotetext{
[...] esta norma mantiene la tradición de los doce años para las faltas relacionadas con las violaciones de los derechos humanos y del derecho internacional humanitario, para lo cual, luego de la interrupción, se tendría un tiempo de tres ańos para notificar y proferir el fallo de segunda instancia (Congreso de la República, Proyecto de Ley No 055 de 2014).
}

Además de lo anterior, se amplía el catálogo de deberes de los funcionarios públicos y demás sujetos disciplinables.

El catálogo que al respecto indica la Ley 734 de 2002, señala sin distinción lo que se considera como falta gravísima. El nuevo proyecto de ley agrupa cada una de estas faltas y las clasifica de acuerdo con la especialidad de cada una de estas y del sujeto 
que las puede cometer. Adicionalmente, reubicó el numeral $1^{\circ}$ del artículo 48 del $\mathrm{CDU}$, referente a la configuración de una falta disciplinaria por la realización de una conducta descrita en un tipo penal objetivo, siendo ello un claro mensaje para la autoridad disciplinaria del deber de examinar la conducta del investigado y confrontarla con la tipología disciplinaria propia, en atención a los principios de especialidad y subsidiariedad referidos anteriormente.

Este aspecto, a juicio de las suscritas, denota un aspecto de gran relevancia e importancia, en tanto se intenta aclararle al operador disciplinario la configuración de un tipo de conducta que conlleva un gran esfuerzo de integración con la dosimetría de la sanción a imponer, como se ha advertido con los casos analizados en presencia, buscando cerrar la brecha del yerro al momento de calificar cierto tipo de conductas denominadas como las más graves al momento de elaborar un pliego de cargos.

\section{Análisis de la jurisprudencia de la Sala Jurisdiccional Disciplinaria}

Ahora bien, hechas las anteriores precisiones, es necesario analizar cómo se ha venido aplicando el principio de proporcionalidad en los casos que se refieren a los funcionarios de la Rama Judicial, a fin de determinar cuál es su comportamiento y cuáles son las falencias que hasta la fecha tiene la legislación en cuanto a la dosimetría de la sanción.

A continuación se realizará un análisis de dos casos en los que se evidencia una violación al principio de proporcionalidad y legalidad.

En el caso $\mathbf{N}^{\circ}$ 1, la falta disciplinaria se origina en un proceso ejecutivo en el Juzgado 13 Civil del Circuito de Bogotá, por el cual la primera instancia decide formular pliego de cargos contra el titular del despacho, por su incursión en la falta disciplinaria consagrada en el "numeral 10 del artículo 153 de la Ley 270 de 1996, en concordancia con los artículos 488, 490, 491, 513 y 681 numeral 11 del Código de Procedimiento Civil como faltas graves a título de culpa, y la falta gravísima contemplada en el artículo 48 numeral $1^{\circ}$ de la Ley 734 del 2002, en concordancia con el artículo 413 de la Ley 599 al desconocer el artículo 303 del Código de Procedimiento Civil”. 
Los hechos originarios de esta imputación, se traducen en que el disciplinado emitió un mandamiento de pago sin que el título ejecutivo estuviese completo y se derivara de este una obligación clara, expresa y exigible, además de no contemplar el mismo una cifra clara, precisa o liquidable de la que se pudiese derivar el valor a pagar. Esta conducta, para la sala de instancia, es analizada como un desconocimiento de los artículos 488 y 490 del Código de Procedimiento Civil, agravada por el aval otorgado por el juzgado a la caución prestada, que era superior al monto autorizado la ley.

De otro lado, la sala de instancia consideró que el disciplinado incurrió en la falta descrita en el numeral $1^{\circ}$ del artículo 48 de la Ley 734 de 2002, pues desconoció el artículo 303 del Código de Procedimiento Civil al revocar su propio auto de mandamiento de pago, sin alegar fundamentos de derecho para ello, y solo remitiéndose a mencionar expresiones externas que le obligaban a revocar tal acto, con la respectiva aceptación de la falta de existencia de un título ejecutivo completo. En atención a ello, la sala de primera instancia sancionó al juez 13 Civil del Circuito de Bogotá por la falta gravísima contemplada en el numeral $1^{\circ}$ del artículo 48 de la Ley 734 de 2002 y le impuso una sanción de destitución e inhabilidad en el escalafón de carrera, así como una inhabilidad general por el término de 15 años.

Esta decisión fue apelada por el disciplinado, siendo resuelta por la Sala Jurisdiccional Disciplinaria del Consejo Superior de la Judicatura en segunda instancia. Frente al primer cargo formulado en la primera instancia, el Consejo Superior de la Judicatura considera que la interpretación realizada es errónea, en tanto no resulta posible que el titular del Juzgado 13 Civil del Circuito hubiese desconocido el artículo 491 del Código de Procedimiento Civil, pues precisamente esta normatividad describe las características de un título ejecutivo y no un comportamiento o conducta a ejecutar, observar u omitir el disciplinado. De otro lado, frente al cargo relativo a haber incurrido en un prevaricato por acción, de lo cual se deriva la falta gravísima concebida en el numeral $1^{\circ}$ del artículo 48 de la Ley 734 de 2002, la Sala Jurisdiccional Disciplinaria del Consejo Superior de la Judicatura observa una carencia de fundamento jurídico.

Además de ello, considera la segunda instancia que la conducta del operador judicial en nada desconoce el ordenamiento jurídico, por el contrario, busca subsanar su 
propio yerro jurídico y encauzar nuevamente el proceso de su conocimiento, lo que dista de ser una falta disciplinable.

Por estas razones, la Sala Jurisdiccional Disciplinaria absuelve de esta falta al disciplinado. Aun así, la segunda instancia mantiene las demás conductas como reprochables e ilícitas por lo que finalmente decide imponer una sanción más acorde con estas, disminuyendo la sanción inicial, a una suspensión por el término de doce (12) meses.

De ese precedente se evidencia que existen yerros en la interpretación realizada en primera y segunda instancias, en lo correspondiente a la adecuación de la sanción, que en definitiva afecta la proporcionalidad de la misma. Como se desprende implícitamente del anterior pronunciamiento, es clara la divergencia entre una posición y otra, derivada de una indebida interpretación de los parámetros fijado en la Ley 734 de 2002, afectando en gran medida el principio de proporcionalidad y legalidad de la sanción, así como los derechos finalmente restringidos a los disciplinados. El anterior razonamiento deriva del hecho de que, la primera instancia consideró como falta disciplinable lo que en realidad constituye un criterio de graduación de la sanción, esto es, intentar enmendar su yerro al revocar su propia decisión, incurriendo el fallador en una abierta violación al principio de legalidad en concordancia con el principio de proporcionalidad.

Otra interpretación de la primera instancia, en la cual se evidencia una afectación al principio de proporcionalidad, se encuentra en el caso No 2 , en el cual la Sala Jurisdiccional Disciplinaria del Consejo Superior de la Judicatura, corrigió un yerro interpretativo de la dosimetría de la sanción y de la calificación de la falta. En esa ocasión, la primera instancia consideró que la calificación de la misma necesariamente debía hacerse a título de dolo, pues la demora injustificada en la resolución de una acción de tutela en el término estipulado por la ley, es dolosa cuando se trata de una juez que lleva una trayectoria en el ejercicio de su cargo, por lo cual resulta impensable que un yerro de este tipo se realice con culpa.

No obstante, esta interpretación realizada respecto del principio de proporcionalidad de la sanción y la misma adecuación típica, nuevamente es objetada por la Sala 
Jurisdiccional Disciplinaria del Consejo Superior de la Judicatura, con los siguientes argumentos:

De igual manera, se tiene dentro de las probanzas que el día 2 de febrero cuando el actor acudió a notificarse de la providencia, esta aún no se encontraba lista, como consta en la certificación que obra a folio 27 del plenario, lo que la doctora CUELLAR RODRÍGUEZ atribuye a un problema con la impresora y una confusión al interior del despacho. Y por lo anterior, "solo se procedió al día siguiente a su respectiva impresión y firma, esto es 3 del presente mes" (febrero de 2009). Argumento que además de carecer de respaldo probatorio alguno, no es de recibo por esta Colegiatura, toda vez que, por mandato constitucional, las acciones de tutela deben ser falladas en 10 días, y que de haberse cumplido con el término nada de lo relatado, confusamente por la juez se hubiera presentado, por lo que se denota culpa en su actuación, pues la mora proviene de un yerro, que sin bien desintencionado, no por ello excusable. Por lo que esta Superioridad no comparte la calificación de DOLO que realizó el a quo y la atenuará a lo previsto para la culpa (Consejo Superior de la Judicatura. Rad. 76001110200020090023902, 2013).

En atención a este nuevo argumento, la segunda instancia modifica la sanción manteniendo la suspensión en el ejercicio del cargo por el término de un (1) mes, pero prescindiendo de la inhabilidad que se había decretado en primera instancia, al haberse calificado la falta como dolosa, cuando del análisis del caso y la falta de material probatorio la conducta investigada obedecía a una culposa, situación que determinó en la variación de la sanción en favor de la investigada.

Esta selección de casos es solo una muestra de la realidad que se presenta en la aplicación del principio de proporcionalidad en las sanciones disciplinarias de los funcionarios de la Rama Judicial, que de por sí evidencian incongruencias en la interpretación, adecuación y tasación de la sanción.

Como se ha planteado en los casos analizados anteriormente, se demuestra que durante el quehacer jurisdiccional disciplinario efectuado por los operadores judiciales de la jurisdicción, se denota un desconocimiento, no en todos los casos, de los parámetros establecidos en el ordenamiento disciplinario del principio de proporcionalidad en todo sentido, encontrándose con una abierta contravención del principio de legalidad, que, evidencia la falta de uniformidad en los criterios de interpretación del principio 
de proporcionalidad de la sanción, y más aún, de la fijación de la misma calificación jurídica en sede disciplinaria, lo cual rompe la unidad establecida por el legislador para ser aplicada en el procedimiento y proceso disciplinario vigente actualmente.

\section{Consideraciones}

\section{Frente al principio de proporcionalidad y su aplicación en el caso de las faltas disciplinarias de los funcionarios de la Rama Judicial}

El principio de proporcionalidad y razonabilidad de las sanciones disciplinarias que procedan por faltas cometidas por funcionarios de la Rama Judicial, deberán ajustarse al principio de legalidad y ser respetuosas de los parámetros de graduación de la falta de acuerdo con los criterios y recomendaciones que para el efecto se determinan en este documento de apoyo, en especial en la etapa de formulación de cargos, donde se han visto las principales falencias de interpretación por parte de los funcionarios encargados de conocer y sancionar este tipo de faltas.

Uno de los elementos a tener en cuenta para la calificación de las faltas, es el grado de culpabilidad con el que se realiza esta o estas según sea el caso, es decir, a título de dolo o culpa, recordándose que toda forma de responsabilidad objetiva se encuentra prohibida en materia de responsabilidad disciplinaria. Se destaca además, que es importante detectar la etapa procesal que brinda al operador disciplinario la oportunidad de calificar la falta, como es el pliego de cargos, con el cual marca la ruta de la instrucción y de la misma investigación y se constituye en un punto neurálgico para el disciplinado, quien debe procurar al igual que el instructor, que se respeten garantías como el debido proceso y el derecho de defensa.

Esta etapa de creación o construcción de la investigación disciplinaria debe estar amparada bajo el principio de legalidad, el cual comporta que en la edificación del pliego de cargos, el operador investigador debe tener claridad de los hechos denunciados, de las pruebas allegadas al plenario, de la valoración de las mismas frente a los hechos que finalmente son comprobados, y que a su vez, constituyen el quebrando del ordenamiento disciplinario para de esta forma dar aplicación a lo normado en el artículo 161 del CDU —Formulación de cargos—, y al estar ante una objetiva de- 
mostración de la falta que comprometa la responsabilidad del investigado, se proceda en los términos del artículo 162 del Código Disciplinario Único, bajo el amparo de la argumentación fáctica, probatoria y normativa que demuestre el quebranto de las normas disciplinarias obligatorias al funcionario judicial, bien sea por acción u omisión, señalando claramente el deber o prohibición que infringió de la Ley 270 de 1996 — principio de legalidad — , y de esta forma señalar claramente que dicho comportamiento constituye una falta disciplinaria — artículo 196 del CDU_, describiendo el tipo de falta según lo descrito en el artículo 42 del mismo código — gravísimas, graves y leves-.

De otra parte, no se puede desconocer el importante papel que ejecuta el operador disciplinario, quien no solamente debe hacer uso de un conocimiento especializado de la materia en la cual impartiría justicia, sino que además debe contar con la experticia y sano juicio jurídico para aplicar la carga normativa que impone la Ley 734 de 2002 para los procesos iniciados contra funcionarios de la Rama Judicial, para lo cual debe contar con una capacitación constante y adecuada por parte de la Escuela Judicial de la Rama Judicial "Rodrigo Lara Bonilla", como herramienta de capacitación y no simplemente quedarse en la existencia de módulos de formación, a los cuales no tienen acceso los administradores de justicia por la carga laboral que enfrentan a diario.

\section{Frente a las faltas disciplinarias de los servidores públicos de la Rama Judicial}

Se considera que el servidor público perteneciente a la Rama Judicial incurre en una falta disciplinaria, cuando transgrede alguna de las faltas descritas de manera general en la Constitución Política, las que se deriven de la legislación que se encuentran conexas con su función (en especial las relacionadas con el debido proceso), y particularmente, las consideradas como prohibiciones y deberes de obligatorio cumplimiento en la Ley 270 de 1996 "Estatutaria de la Administración de Justicia”, o aquellas que se consideren como un incumplimiento injustificado de los deberes y funciones encomendados en función de su cargo, la extralimitación en el desempeño de sus funciones o derechos y la violación de lo dispuesto por la ley en mate- 
ria de incompatibilidades, impedimentos, conflictos de intereses, impedimentos e inhabilidades.

El funcionario competente debe tener en cuenta, además del grado de culpabilidad con el que se comete la falta, la modalidad con la que esta se realiza, es decir, por acción u omisión.

Resulta de gran importancia que el operador disciplinario atienda al momento de la calificación de la falta: i) el catálogo expreso del artículo 48 del CDU —Faltas gravísimas-, mediante una labor de descarte, para saber si allí encaja la conducta y la falta se considera gravísima, en caso contrario la falta será grave o leve de acuerdo con los criterios contenidos en el artículo 43 del CDU —Criterios para determinar la gravedad o levedad de la falta_-, ii) que al momento de la práctica de pruebas en sus investigaciones no deben indagar exclusivamente sobre la falta y la responsabilidad sino también de cara a los criterios de graduación de la sanción, para que al dosificar cuenten con elementos de juicio ciertos y no se especule con ellos y, iii) tener claridad sobre lo normado en los artículos 46 y 47 de la Ley 734 de 2002, en tanto es en este momento en que cobra mayor relevancia el principio de proporcionalidad, mientras se comienza a conjugar y analizar la prevalencia de otros principios como el de legalidad y debido proceso en el caso en estudio, y de esta forma, se asegura una mayor comprensión del asunto y un resultado óptimo para el investigado y la enseñanza que se dejará a la sociedad que demanda justicia.

\section{Frente a la calificación de la falta}

En primer lugar, el funcionario que conoce de la investigación debe determinar el autor de la falta disciplinaria y en qué calidad lo hace. Con ello se refiere a si es directamente el funcionario de la Rama Judicial quien lo realiza, o si este es quien determina a un tercero a realizarla, sin importar si los efectos de la conducta que constituye falta disciplinaria se producen durante o después de la dejación de las funciones o del cargo. Es importante este punto para no incurrir en ambigüedades o arbitrariedades en el ejercicio disciplinario de impartir justicia, pues como se advirtió en los casos analizados en este artículo, este elemento juega un papel importante al momento de la imposición de una sanción disciplinaria, pues al incurrir en yerros 
en la investigación, se rompe con la máxima de una investigación integral afectando derechos constitucionales de los investigados.

El segundo elemento que se debe analizar, identificado el autor dentro de la esfera de los operadores disciplinarios, es si existe o no una causal de exclusión de la responsabilidad del servidor público, las cuales se encuentran consagradas en el artículo 28 de la Ley 734 de 2002. De acreditarse la existencia de por lo menos una de estas, se deberá desistir de la acción disciplinaria; en caso contrario, se deberá proceder a la calificación de la falta, la cual, de acuerdo con el artículo 42 de la Ley 734 de 2002 puede ser gravísima, grave y leve. En el caso de las faltas gravísimas estas se encuentran enunciadas explícitamente en la Ley 734 de 2002.

\section{Frente a los criterios de determinación de la gravedad o levedad de la falta disciplinaria del funcionario de la rama judicial}

Los criterios de determinación de la gravedad o levedad de la falta, se encuentran enunciados en el artículo 43 de la Ley 734 de 2002 y de la evaluación de los mismos, se deriva con mayor frecuencia la subjetividad de interpretaciones que dan al traste con violaciones al principio de proporcionalidad y legalidad; de ahí que sea necesario recomendar algunos parámetros generales de interpretación que contribuyan con una correcta determinación de la gravedad o levedad de la falta, en algunos casos donde la ley no es clara frente a las condiciones en que se debe calificar la falta, máxime cuando de ello depende la sanción que se impone.

Así pues, frente al grado de culpabilidad, debe determinarse si la conducta cumple con los elementos de dolo o de culpa, mientras que, tratándose de la naturaleza esencial del servicio, se debe tener en cuenta el grado de incidencia o impacto que tuvo la conducta, en qué etapa procesal se produce, cuáles son los efectos para las partes, la afectación de principios de importancia como el debido proceso y aquellos que se desprenden de este, entre otros elementos.

De cara al grado de perturbación del servicio y el criterio de jerarquía y mando del servidor público en la Rama Judicial, estos aspectos deben ser evaluados consideran- 
do cada uno de los procesos que se llevan a cabo en las diferentes jurisdicciones y considerando la diversidad de plantas conformadas en cada despacho judicial.

Respecto de la trascendencia social de la falta o el perjuicio causado, deben evaluarse: i) la trascendencia social y, ii) el perjuicio causado, evaluando el impacto de la acción u omisión en la sociedad, y las consecuencias de la conducta disciplinable.

Frente a las modalidades y circunstancias en que se comete la falta, debe revisarse detalladamente la forma en la que se consumó la conducta u omisión, incluido el criterio de grado de participación y de influencia de un tercero y los motivos que determinaron el comportamiento.

Finalmente, frente a la realización de la falta objetivamente gravísima, debe considerarse el impacto que tiene la falta dentro de cada proceso judicial y la protección de la correcta administración de justicia en el evento en que la falta tenga un impacto tal que objetivamente sea gravísima, aun cuando no se encuentre dentro del catálogo descrito por la ley disciplinaria.

Se reitera que, si el operador disciplinario aplica de forma adecuada estas reglas para determinar los criterios de gravedad o levedad de la falta, dicha actuación trasciende de manera absoluta en la graduación de la sanción dentro de los límites del artículo 46 del CDU, con lo cual se aseguraría una unificación ${ }^{6}$ pacifica de las decisiones emitidas por los a quo toda vez que su superior jerárquico no tendría que entrar a modificar sus decisiones ante los desconocimientos de las normas disciplinarias, asegurándose así una mayor seguridad jurídica dentro de las decisiones emitidas por la Jurisdicción Disciplinaria.

$6 \mathrm{Al}$ respecto, es importante hacer referencia a lo dispuesto por Vargas (2018), para quien: "Un propósito de la Ley 1437 de 2011, fue la implementación de figuras jurídicas novedosas, como la extensión de la jurisprudencia del Consejo de Estado y el recurso extraordinario de unificación de la jurisprudencia, mecanismos judiciales con los cuales se busca dotar al ciudadano de herramientas que le permitan encontrar respuestas expeditas por parte de las autoridades, en casos en los cuales el Consejo de Estado haya proferido sentencias de unificación, de modo que no sea necesario acceder a la vía jurisdiccional, en la medida en que la petición sea favorable” (p. 141). 


\section{Frente a la clasificación y límite de las sanciones disciplinarias}

El actual Código Único Disciplinario, aun cuando establece los límites mínimos y máximos de las sanciones, no señala criterios claros para su asignación en cada caso particular. Ello es subsanado parcialmente con el nuevo texto del proyecto de ley del nuevo Código Único Disciplinario, en su artículo 48.

Ahora, la calificación del grado de culpabilidad en la dosificación de la sanción, es un elemento que contribuye a la existencia de una mayor proporcionalidad en la imposición de la sanción, limitando en alguna medida la discrecionalidad del juez disciplinario. Sin embargo, actualmente el ordenamiento disciplinario no permite hacer un análisis exclusivo de mínimos y máximos como ocurre en el derecho penal, por lo cual los criterios establecidos por el legislador en la Ley 734 de 2002, se enmarcan en todo el trabajo de construcción o edificación de la falta en el pliego de cargos. Así las cosas, la carga de interpretación del fallador disciplinario se incrementa, siendo necesario que este cuente con herramientas más expeditas para establecer líneas de sanciones impuestas a casos similares y de esta forma, no incurrir en desproporciones al momento de resolver asuntos que ya fueron tratados en idénticos fácticos, pero que contaron con sanciones diferentes incluso en contravía del principio de proporcionalidad.

\section{Elaboración de una herramienta que permita un seguimiento a las sanciones impuestas en la Jurisdicción Disciplinaria}

En suma, se puede considerar que, si bien el operador disciplinario tiene una alta carga de responsabilidad en la protección de principios constitucionales, lo cierto es que este debe contar con las herramientas necesarias para establecer una línea jurisprudencial que le permita poder acceder a una información consolidada, histórica y precisa de cómo se han resuelto asuntos similares para no ir en contravía de las mismas decisiones judiciales que emite la Jurisdicción Disciplinaria.

Esto conlleva a exigir o demandar una fuerte tarea de sistematización de las decisiones de los Consejos Seccionales, en aras de que no solamente estos cuenten con una herramienta, sino además los investigados y la misma sociedad, concretándose un 
trabajo mancomunado que evitará que se emitan decisiones claramente contradictorias como se evidenció en los casos analizados en esta investigación.

\section{El nuevo Código General Disciplinario}

Si bien se prepara una nueva codificación disciplinaria en aras de corregir muchos de los yerros originados en la norma actual, no resulta menos cierto que en caso de su promulgación, el proyecto de ley posiblemente se enfrentaría a las mismas vicisitudes que actualmente enfrenta la Ley 734 de 2002, en tanto al revisar el articulado de las faltas y sanciones disciplinarias, la variación no es muy significativa, limitándose a hacer algunas precisiones o aclaraciones sobre atenuantes y agravantes, manteniendo la estructura misma de la Ley 734 de 2002, dejando nuevamente a discrecionalidad del operador disciplinario su interpretación y aplicación a los casos que debe resolver, situación que probablemente mantendría el mismo escenario que hoy enfrentan los jueces disciplinarios.

Esto quiere decir que la problemática no se centra en lo dispositivo de la norma, sino en el ejercicio constante de conocimiento y entendimiento que debe realizar el juez disciplinario para enfrentar los procesos que están a su cargo y de esta forma, aplicar los criterios constitucionales que imperan las actuaciones disciplinarias evitando transgredir el principio de proporcionalidad al momento de la imposiciones de sanciones, entre otros, con lo cual no podemos considerar que para cada mal advertido se debe crear una norma, cuando lo que se debe atacar o evitar es la falta de conocimiento de nuestros operadores disciplinarios.

\section{ConClusiones}

A manera de conclusión, podemos afirmar que, al ser el derecho disciplinario un mecanismo a través del cual el Estado ejercer el ius puniendi, su regulación por parte del legislador ha estado orientada a garantizar los presupuestos propios del principio de proporcionalidad, legalidad y derecho del debido proceso. Resultado de ello es la norma sustancial y procedimental en la que se consagran los principios, derechos, 
deberes, prohibiciones, faltas, sanciones y procedimientos a los que se encuentran sujetos los funcionarios públicos.

Aun así, se considera que persisten ambigüedades que provienen del actual Código Único Disciplinario que mantienen un ámbito de ejercicio discrecional del instructor disciplinario. En ese sentido y para dar respuesta al problema de investigación planteado, se puede concluir, luego de haber analizado los casos enunciados en este artículo, que en el marco jurídico actual del derecho disciplinario no se garantiza la aplicación adecuada del principio de proporcionalidad en las sanciones disciplinarias impuestas a los funcionarios de la Rama Jurisdiccional del Poder Público.

Es por ello que se consideró necesario proponer algunas consideraciones como resultado de la investigación, con el ánimo de propiciar espacios o escenarios en los cuales los operadores disciplinarios cuenten con herramientas, capacitaciones y una experiencia que les permita adoptar decisiones judiciales con apego a los principios de proporcionalidad y legalidad, esto quiere decir, que dicha tarea es una ejercicio constante de crecimiento, que en la actualidad se presentan muchas falencias, pero que pueden ser enmendadas mientras es aprobado el nuevo Código General Disciplinario, como es contar con una herramienta consolidada de relatorías a nivel de los Consejos Seccionales del país para la consulta permanente del a quo, con acceso incluso a la relatoría de su superior jerárquico en aras de edificar precedentes más acordes y concretos con los casos que conocen a diario; además de contar por parte de la Escuela Judicial Rodrigo Lara Bonilla, con estrategias de capacitación más efectivas y certeras a las necesidades de los magistrados y de todos sus colaboradores encargados de la sustanciación de providencias judiciales, con el ánimo de que los casos sean resueltos en su mayoría por personas y profesionales conocedores de las normas que imperan o gobiernan el procedimiento disciplinario y de esta forma, no desconocer principios tan importantes como el de proporcionalidad al momento de la elaboración del pliego de cargos y su consecuente fallo o sentencia judicial.

Todo esto con el ánimo de lograr una mayor seguridad jurídica al interior de la Jurisdicción Disciplinaria y la concreción de decisiones judiciales emitidas con apego a la Constitución y la ley. 


\section{REFERENCIAS}

Bahamón, X., y Gómez, Y. (2017). El activismo judicial en el proceso disciplinario. Revista IUSTA, 2(47), 143-163. DOI: http://dx.doi.org/10.15332/s1900-0448.2017.0047.06. Recuperado de http://revistas.usta.edu.co/index.php/iusta/article/view/3807/3746

Bonilla, H. (2018). Sugerencias para la primera reforma al Código General del Proceso (Ley 1564 de 2012). Revista Via Inveniendi et Iudicandi, 13(1), 217-236. DOI: http://dx.doi. org/10.15332/s1909-0528.2018.0001.08. Recuperado de http://revistas.usantotomas. edu.co/index.php/viei/article/view/4272/4049

Congreso de la República. (2000). Proyecto de Ley No 19 de 2000, por el cual se expide el Código Disciplinario Único. República de Colombia, Rojas Jiménez, H. H. et ál., Gaceta del Congreso No 291, 2000.

Congreso de la República. (2014). Proyecto de Ley No 055 de 2014, Por el cual se expide el Código Disciplinario Único. República de Colombia, Lozano Correa, A. L. et ál., Gaceta del Congreso No 842, 2014.

Consejo Superior de la Judicatura. (2013). Sala Jurisdiccional Disciplinaria. Sentencia del 30 de enero de 2013, expediente 76001110200020090023902. República de Colombia, Bogotá D. C., Diario Oficial.

Consejo Superior de la Judicatura. (2014). Sala Jurisdiccional Disciplinaria. Sentencia del 19 de febrero de 2014, expediente 11001110200020090568902 . República de Colombia, Bogotá D. C., Diario Oficial.

Corte Constitucional. (1998). Sentencia de constitucionalidad C-160 de 1998, expediente D-1841. República de Colombia, Bogotá D. C., Diario Oficial.

Corte Constitucional. (2001). Sentencia de constitucionalidad C-653 de 2001, expediente D-3313. República de Colombia, Bogotá D. C., Diario Oficial.

Corte Constitucional. (2003). Sentencia de constitucionalidad C-125 de 2003, expediente D-4059. República de Colombia, Bogotá D. C., Diario Oficial.

Corte Constitucional. (2004). Sentencia de tutela T-1093 de 2004, expediente T-791349. República de Colombia. Bogotá D. C., Diario Oficial. 
Corte Constitucional. (2006). Sentencia de constitucionalidad C-393 de 2006, expediente D-6042. República de Colombia. Bogotá D. C., Diario Oficial.

Corte Constitucional. (2006). Sentencia de constitucionalidad C-738 de 2006, expediente D-6194. República de Colombia. Bogotá D. C., Diario Oficial.

Corte Constitucional. (2015). Sentencia de constitucionalidad C-328 de 2015, expediente D-10489. República de Colombia, Bogotá D. C., Diario Oficial.

García Gómez de Mercado, F. (2007). Sanciones administrativas: garantías, derechos y recursos del presunto responsable. Granada, España: Editorial Comares.

Hernández, O. (2018). La segunda instancia: una probabilidad de la sentencia en mínima cuantía. Revista Via Inveniendi et Iudicandi, 13(1), 189-215. DOI: http://dx.doi. org/10.15332/s1909-0528.2018.0001.07. Recuperado de http://revistas.usantotomas. edu.co/index.php/viei/article/view/4271/4048

Huertas, O., Rumbo, C., y Uribe, A. (2018). El juez de vigilancia penitenciaria en España, como referente de la ejecución penal en América Latina. Revista IUSTA, 1(48), 73-96. DOI: https://doi.org/10.15332/s1900-0448.2018.0048.03. Recuperado de http://revistas.usta.edu.co/index.php/iusta/article/view/4087/3882

López Mora, M. M. (2013). Acerca del principio de proporcionalidad en la dosimetría de la sanción disciplinaria. Bogotá D. C., Colombia: Ediciones Nueva Jurídica.

Montero, D. (2017). Derecho disciplinario militar y derechos humanos en Colombia 20042014. Revista Via Inveniendi et Iudicandi, 12(1), pp. 37-65. Recuperado de http://revistas.usantotomas.edu.co/index.php/viei/article/view/3563/3451

Ramírez Torrado, M. L. (2010). Reflexiones acerca del principio de proporcionalidad en el ámbito del derecho administrativo sancionador colombiano. Revista Estudios SocioJurídicos, 12(1). Recuperado de http://www.redalyc.org/pdf/733/73313677008.pdf

Roa Salguero, D. A. (2014). El principio de proporcionalidad cortapisa al abuso de la potestad disciplinaria. Revista de Derecho Penal y Criminología, 35(99), 139-156. Recuperado de file://C:/Users/Usuario/Downloads/4400-18624-1-PB.pdf

Santamaría Pastor, J. A. (2004). Principios de derecho administrativo general. Segundo Tomo. Madrid, España: Editorial Iustel. 
Vargas, S. (2018). La fuerza vinculante de la jurisprudencia del Consejo de Estado. Revista IUSTA, 1(48), 119-144. DOI: https://doi.org/10.15332/s1900-0448.2018.0048.05. Recuperado de http://revistas.usta.edu.co/index.php/iusta/article/view/4089/3884

Valdés Palacios, L. E., Cárcamo Calderón, A., Tirado González, A., Osorio Patiño, F., y Muñetón Vasco, O. (2007). El principio de proporcionalidad en el ámbito de las sanciones disciplinarias en Colombia. En Lecciones de derecho disciplinario, volumen II. Procuraduría General de la Nación. Bogotá D. C., Colombia: Imprenta Nacional de Colombia. 